\title{
30 A CONTRIBUTION TO UNDERSTAND COLLABORATION BENEFITS
}

\author{
Luis M. Camarinha-Matos, António Abreu \\ New University of Lisbon \\ Quinta da Torre - 2829 Monte Caparica, PORTUGAL \\ cam@uninova.pt, aifa@,fct.unl.pt
}

\begin{abstract}
The identification and characterization of collaboration benefits is an important element for the wide adoption of the collaborative networks paradigm. Departing from some categorization of intuitive advantages of collaboration, this paper introduces an approach for the analysis of benefits in collaborative processes for enterprises networks. The potential application of some indicators derived from this analysis is also discussed in VO breeding environment (VBE) context.
\end{abstract}

\section{INTRODUCTION}

In most literature on Virtual Enterprises / Virtual Organizations there is an intuitive assumption that these forms of collaborative networks bring clear advantages to its members and represent even a survival factor in turbulent socio-economic scenarios. However, in spite of this assumption, it is also frequently mentioned that the lack of objective measurements, clearly showing the benefits of such organizational forms, is an obstacle for a wider acceptance of this paradigm.

What will my organization benefit from embarking in a collaborative network? Will the benefits compensate for the extra overhead and even the risks that collaboration implies? These are questions that many SME managers ask when the issue of collaboration is brought in.

It is, in fact, difficult to prove the advantages of (dynamic) collaborative networks in contrast to more traditional organizational forms in terms of improved performance. Being able to measure the performance of a collaborative network as a whole and the performance of each of its members could represent an important boosting element for the wide acceptance of the paradigm. However performance indicators tailored to collaborative networks are not available yet [6].

Performance measurement depends on the premises of the measurement system used. Collaborative networks challenge the premises of the methods developed in the past, therefore the applicability of existing measurement systems in this area is questionable.

Before establishing a new set of indicators it is necessary to analyze in more detail the basis of collaboration and its benefits. Understanding the nature of 
collaboration benefits is also important as a way to ensure that every member of the network understands the measurements in the same way. This is also a requirement for goals alignment in order to facilitate the coherence of members' goals with the measurements.

This paper introduces some discussion of the nature of collaboration benefits as a contribution to a future identification of a set of performance indicators that are suitable for collaborative networks.

\section{SOME BACKGROUND}

A number of theories focused on different perspectives of cooperation have been proposed in various disciplines. Some relevant examples include:

- Resource Dependence theory - which is concerned with the arrangements between enterprises to reduce uncertainty and dependency from products, services, tangible and intangible resources and competencies, to contribute to the creation of their offerings to customers. From this theory point of view, cooperation is explained as an attempt of the enterprises to adapt to their environments to enable the procurement of necessary resources while at the same time maintaining acceptable power-dependency relationship $[5,11]$.

- Transactions cost theory - Transactions costs are generally defined as being the cost for gathering information, negotiation and contracting, and physical transaction of objects through a defined interface. According to this theory, enterprises and markets are alternative governance structures that differ in their transactions costs. From this point of view cooperation is explained as an organizational "hybrid" form between the market and the enterprise [14].

- Game theory - A mathematical framework designed for analyzing the interaction between several actors whose decisions affect each other. An interactive situation is described as a game including an abstract description of the players (actors), the courses of actions available to them, and their preferences over the possible outcomes. From this perspective, cooperation processes take place when the total utility of acting in conjunction is greater than the sum of utilities for each participant considered individually $[1,8]$.

- Complexity theory - Complexity theory deals with systems that show complex structures in time or space, often hiding simple deterministic rules. A complex system can be understood as any network of interacting agents (processes or elements) that exhibits a dynamic aggregate behavior as a result of the individual activities of its agents. Some important characteristics of complex systems include: non-determinism, limited functional decomposability, distributed nature of information, and emergence and self-organization. Emergence is in fact one of the most important properties of complex systems, what makes this paradigm an appealing approach for the analysis of advanced collaborative networks $[2,7,9,12]$.

- Contingency theory - Contingency theory is concerned with the identification and understanding of the enterprise structure in different conditions (or contingencies). Various forms of organization can coexist depending on different conditions. These conditions depend on internal factors that are specific to each enterprise but also external factors like: the environment uncertainty and the 
distribution of resources. This theory considers a cooperation process as a fast way for an enterprise to quickly adjust its structure to an environment with high uncertainty [10].

Although offering some structuring elements, these theories are mostly "enterprisecentric" (except the theory of complexity and game theory) and lack an interorganizational focus.

Some other more "network-centric" contributions can be found in various works from the sociology area dealing with "social actors networks". In this area concepts such as prominence of actors in a network, centrality, prestige, etc. and approaches to compute them have been suggested [13]. These approaches are perhaps more abstract, lacking some economic and practical focus, but can be used as a source of inspiration to analyze collaborative networks of enterprises.

From the traditional literature on virtual enterprises / virtual organizations, a number of variables related to the identification of collaboration benefits have been suggested (Table 1).

Table 1 - Cooperation variables and associated target goals

\begin{tabular}{|c|c|}
\hline 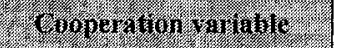 & ard \\
\hline $\begin{array}{l}\text { Costs } \\
\text { Risks } \\
\text { Dependence } \\
\text { Innovation } \\
\text { Market position } \\
\text { Flexibility } \\
\text { Agility } \\
\text { Specialization } \\
\text { Regulation } \\
\text { Social causes }\end{array}$ & $\begin{array}{l}\text { Share costs } \\
\text { Share risks } \\
\text { Decrease the dependence level in } \\
\text { relation to third party } \\
\text { Increase innovation capacity } \\
\text { Defend a position in the market } \\
\text { Increase flexibility } \\
\text { Increase agility } \\
\text { Increase specialization } \\
\text { Establish proper regulations } \\
\text { Share social responsibility }\end{array}$ \\
\hline
\end{tabular}

Table 2 shows, for each target goal, some examples of associated (intuitive) advantages of collaboration.

Table 2 - Example of some associated advantages

\begin{tabular}{|c|c|}
\hline nget & 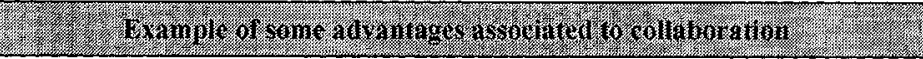 \\
\hline Share costs & $\begin{array}{l}\text { - Have access to new markets and/or businesses without the need to make } \\
\text { high investments. } \\
\text { - Share R\&D costs. } \\
\text { - Ability for SMEs to compete with large competitors. }\end{array}$ \\
\hline Share risks & $\begin{array}{l}\text { - Companies operate in changing environments and with limited, therefore } \\
\text { imperfect, knowledge. Consequently in some cases the level of uncertainty } \\
\text { may have a negative impact on the decision-making processes. Sharing } \\
\text { knowledge among several partners allows a reduction of this uncertainty } \\
\text { level. } \\
\text { - When several partners are involved in a collaborative project there is a } \\
\text { partition of the responsibilities among them (co-responsibility). } \\
\text { - In some cases solidarity mechanisms can be established among partners. } \\
\text { - Also enabling the competition of SMEs with large companies. }\end{array}$ \\
\hline
\end{tabular}




\begin{tabular}{|c|c|}
\hline $\begin{array}{l}\text { Decrease the } \\
\text { dependence level } \\
\text { in relation to third } \\
\text { party }\end{array}$ & $\begin{array}{l}\text { - All companies depend on others to some extent for products, services, raw } \\
\text { materials, tangible and intangible resources and competencies. Through } \\
\text { cooperation companies can reduce this dependence by creating privileged } \\
\text { links to other firms in an attempt to reduce transaction costs that arise when } \\
\text { uncertainty increases. } \\
\text { - Also enabling the competition of SMEs with large companies. }\end{array}$ \\
\hline $\begin{array}{l}\text { Increase the } \\
\text { innovation } \\
\text { capacity }\end{array}$ & $\begin{array}{l}\text { - Increase the capacity of generating new ideas through the combination of } \\
\text { the existent resources and diversity of cultures and experiences (critical } \\
\text { mass). } \\
\text { - Emergence of new sources of value. } \\
\text { - Reduction of the life cycle of the products and technologies. } \\
\text { - Possibility of developing more robust products fitting the customers' } \\
\text { expectations and therefore contributing to an increase of the quality. }\end{array}$ \\
\hline $\begin{array}{l}\text { Defend a position } \\
\text { in the market }\end{array}$ & $\begin{array}{l}\text { - Achievement of economies of scale by sharing resources. } \\
\text { - Establishment of d efensive coalitions with the purpose of building entry } \\
\text { barriers in order to defend themselves against a dominant firm or a new } \\
\text { player. } \\
\text { - Establishment of offensive coalitions with the purpose of developing } \\
\text { competitive advantages and strengthening their position by diminishing the } \\
\text { other competitors' competitiveness. } \\
\text { - Increase the negotiation power in relation to suppliers and/or customers } \\
\text { that are outside of the collaborative network. } \\
\text { - Also enabling the competition of SMEs with large companies. }\end{array}$ \\
\hline $\begin{array}{l}\text { Increase } \\
\text { flexibility }\end{array}$ & $\begin{array}{l}\text { - Share of resources and combination of skills among partners. } \\
\text { - Use the core competences from other partners. } \\
\text { - Increase the adaptation capacity towards several business environments } \\
\text { simultaneously. } \\
\text { - Offer a broader range of products / services. } \\
\text { - Grow for new segments in a stable way reaching a larger stability. }\end{array}$ \\
\hline Increase agility & $\begin{array}{l}\text { - React in a short period of time to a business opportunity through the } \\
\text { establishment of more agile procedures. } \\
\text { - Increase the interoperability between several processes and products } \\
\text { (establishment of norms) }\end{array}$ \\
\hline $\begin{array}{c}\text { Increase } \\
\text { specialization }\end{array}$ & - Let companies concentrate their resources on the critical activities. \\
\hline $\begin{array}{l}\text { Establish proper } \\
\text { regulations }\end{array}$ & $\begin{array}{l}\text { - Definition of rules to avoid opportunistic behaviors and to avoid conflicts. } \\
\text { - Increase common culture of trust. }\end{array}$ \\
\hline $\begin{array}{l}\text { Share social } \\
\text { responsibilities }\end{array}$ & $\begin{array}{l}\text { Obtain recognition from others (intangible value) } \\
\text { - } \\
\text { - } \\
\text { Altruism. } \\
\text { Reinforce values that are common. }\end{array}$ \\
\hline
\end{tabular}

From a macro-level, these potential benefits can be regarded from two perspectives:

- Survival capacity - Reflecting the capacity of an actor (e.g. company) or a group the actors to stay in operation "alive" when confronted by forces, which tend to destroy them.

- Performance capacity - Reflected in the capability of a $\mathrm{n}$ actor or groups the actors to better accomplish their tasks.

One question is then whether each of the above potential benefits of collaboration is more relevant to a situation of survival or performance improvement. In order to identify possible answers, a small survey ( 45 respondents) was conducted by email, involving industry and academia experts from Portugal, Italy, Spain, Germany, UK, Denmark, Turkey, Austria, USA, Canada, and Japan. Fig. 1 shows an excerpt of the used questionnaire.

Fig. 2 summarizes the collected answers. The adopted scale considers the 
following:

- Strong relationship - When the distribution of most answers in relation to the variable is in the interval of $75 \%$ to $100 \%$ of relevance.

- Moderate relationship - When the distribution of most answers in relation to the variable is in the interval of $25 \%$ to $50 \%$ of relevance, or in the interval of $50 \%$ to $75 \%$ of relevance.

- Weak relationship - When the distribution of most answers in relation to the variable is in the interval of $0 \%$ to $25 \%$ of relevance.

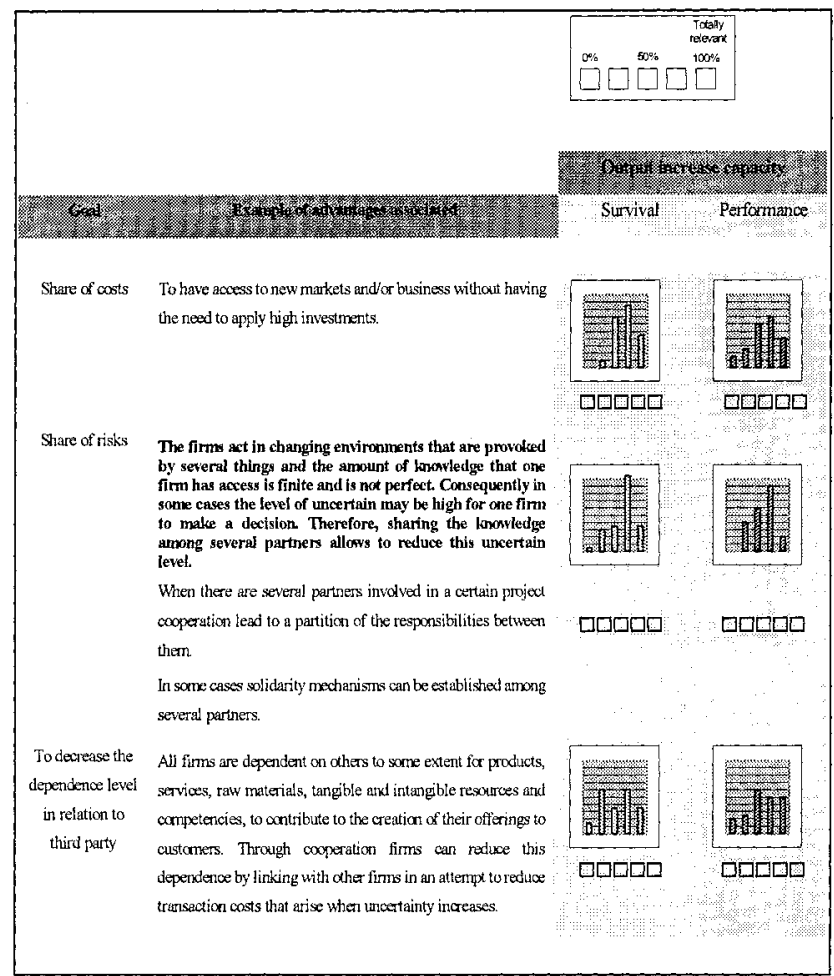

Figure 1-Excerpt of the questionnaire and collected answers

\begin{tabular}{|c|c|}
\hline & Benefits effects \\
\hline Target goal & \begin{tabular}{l|l} 
Survlval & Performance \\
\end{tabular} \\
\hline Share of costs & 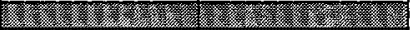 \\
\hline Share of risks & 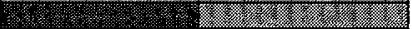 \\
\hline To decrease the dependence level in reiation to third party & 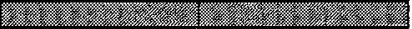 \\
\hline Increase the innovation capacity & 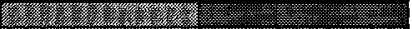 \\
\hline To defend a position in the market & 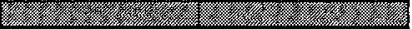 \\
\hline Increase the flexibility & (2) \\
\hline Increase the agility & \\
\hline Increase the specialization & \\
\hline Regulation & 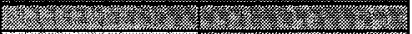 \\
\hline Social causes & 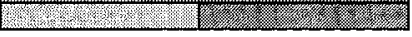 \\
\hline & $\begin{array}{l}\text { Strong Relationship } \\
\text { Moderate Relationship } \\
\text { Weak Relationship }\end{array}$ \\
\hline
\end{tabular}

Figure 2 - Contribution of benefits to survival and performance increase 
From these results one can conclude there is a clear (intuitive) perception that cooperation benefits are related to the two strategic goals - survival or performance increase.

It is also visible that if the primary goal of a company is to stay "alive" it would likely be motivated to find cooperating partners with the purpose of sharing risks. On the other hand, if the strategic goal is to improve performance, the motivation for partnership will be more related to increasing innovation capacity. Increasing flexibility, agility, and specialization are equality important in both cases.

\section{BENEFITS ANALYSIS}

\subsection{Task performance benefits}

For the purpose of the following discussion, let's consider Task Performance Benefits (TB) as the benefits that result from the performance of a task in the context of a collaborative process. A collaborative process is understood as a set of tasks performed by the collaborative network members towards the achievement of a common goal (e.g. the business goal that motivates the creation of a Virtual Enterprise). For reasons of simplicity we consider a level of granularity of tasks such that each task is performed by a single member of the network (single actor).

The term benefit is used with the same meaning as net profit. In the following analysis benefits are assumed as abstract quantifiable measurements. The actual meaning of a benefit depends on the underlying value system. For instance, in the context of networks of enterprises it most likely represents a measure of economic benefits while in the context of a NGO it could represent a more abstract indication of social prestige or peer recognition. In general this concept represents a combination of multiple variables (as discussed in previous section). How to combine those variables into a single value is not addressed in this paper.

Let $T B_{j i}\left(t_{j l}\right)$-benefits for actor $a_{i}$ as a result of the performance of task $t_{l}$ by an actor $a_{j}$.

When $i=j$ this represents a self-benefit (Fig. 3.a); otherwise it is a received benefit (perspective of $a_{i}$ ) or contributed benefit (perspective of $a_{j}$ ) (Fig. 3.b).

In the context of a collaborative network the total self-benefits for a given actor $a_{i}$ is given by the sum of the self-benefits obtained from all tasks performed by this actor: $\quad$ Self Benefits $\left(S B_{i}\right)=\sum_{i=1}^{L} T B_{i i}\left(t_{i l}\right)$

where: $\quad t_{i l}$-description of a task $t_{l}$ performed by actor $a_{i}$

$L$ - total of task performed by actor $a_{i}$

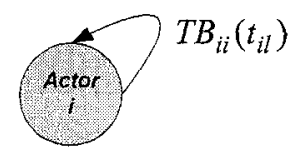

Figure 3 - a) Self benefits for actor $A_{i}$

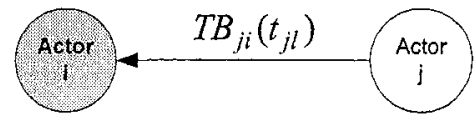

b) Actor $A_{i}$ receives benefits from actor $A_{j}$ 
The total of the benefits an actor $a_{i}$ receives as a result of the performance of another actor $a_{j}$ is given by:

Received Benefits $\left(R B_{i j}\right)=\sum_{l=1}^{L} T B_{j i}\left(t_{j l}\right) \quad i \neq j$

where: $\quad t_{j l}$-description of a task $t_{l}$ performed by actor $a_{j}$

$L$ - number of tasks performed by actor $a_{j}$

And the benefits received (external benefits) by an actor $a_{i}$ as a result of the performance of all actors involved in the cooperation process is given by:

External Benefits $\left(E B_{i}\right)=\sum_{j=1}^{N} R B_{i j} \quad i \neq j$

where: $\quad \mathrm{N}-$ Number of actors involved in the collaborative network.

The external benefits, i.e. what an actor perceives as direct benefit of collaboration, shall be $>0$. O ne a ctor might a ccept a n on-positive $v$ alue for $\mathrm{s}$ ome collaboration processes, but in the long run the result needs to be positive in order to keep it interested in collaboration.

The total benefits for $a_{i}$ are: Total individual benefits $\left(T I B_{i}\right)=\mathrm{SB}_{\mathrm{i}}+\mathrm{EB}_{\mathrm{i}}$.

From the network point of view, the total received benefits are:

Total Received Benefits $(T R B)=\sum_{j=1}^{N} E B_{i}$

Similarly, from the contributor point of view we can define: Benefits contributed by an actor $a_{i}$ to its partner $a_{j}$ as a result of all tasks performed by $a_{i}$ :

Contributed Benefits $\left(C B_{i j}\right)=\sum_{i=1}^{L} T B_{i j}\left(t_{i l}\right) \quad i \neq j$

where: $\quad t_{i l}$-description of a task $t_{l}$ performed by actor $a_{i}$

$L-$ total tasks performed by actor $a_{i}$

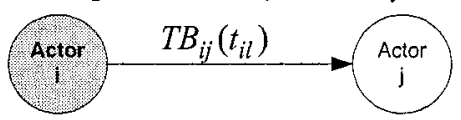

Figure 4-Actor $a_{i}$ contribute benefits to actor $a_{j}$.

And the sum of benefits contributed (social contributed benefits) by an actor $a_{i}$ to all its partners as a result of its performance in the cooperation process is given by:

Social Contributed Benefits $\left(S C B_{i}\right)=\sum_{j=1}^{N} C B_{i j} \quad i \neq j$

where: $\quad \mathrm{N}$ - Number of actors involved in the collaborative network.

In a sustainable collaboration network, at least in the long term, $\mathrm{SCB}_{\mathrm{i}}$ shall be $>0$, otherwise the actor would be considered selfish.

Total benefits resulted from an actor $a_{i}$ :

Individual Generated Benefits $\left(I G B_{i}\right)=S B_{i}+S C B_{i}$ 
From the network point of view, the total contributed benefits are:

Total Contributed Benefits $(T C B)=\sum_{j=1}^{N} S C B_{i}$

Obviously, the total received benefits $=$ total contributed benefits, i.e. $T R B=T C B$. In a sustainable collaborative network these benefits shall be greater than 0 .

\subsection{Task dependence}

There is a task dependence when the realization of a task by one actor, and therefore the respective benefits, depends on other agents that are not involved in the execution but have an influence on that execution. An example of task dependence occurs when an actor with a good reputation in the market is present as member of a collaborative network and this fact helps others to acquire a contract (task) that otherwise would be lost.

This task dependence (or influence from some actors) can be modeled as an enabling factor with a value between 0 (inhibitor) and 1 (enabler). The benefits resulting from a dependent task are therefore conditioned by this enabling factor:

Dependable Task Benefits DTB ${ }_{i j}\left(t_{i m}\right)=T B_{i j}\left(t_{i m}\right) \times \prod_{d=1}^{K} D_{d i}$

where: $\quad \mathrm{K}$ - actors that influence task $t_{i m}$

It shall be noted however that this expression does not properly model all dependency situations. For instance, it does not capture the cases in which the influences of two or more actors are addictive. What if two actors with positive influence "compensate" for one with negative influence? This formula gives predominance to the negative influence (any value of $D_{d i}$ less than 1 represents some form of negative influence).

One possibility is to consider different types of dependencies (Fig. 5):

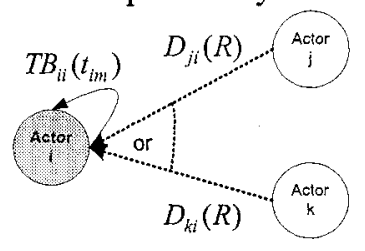

"or" influences

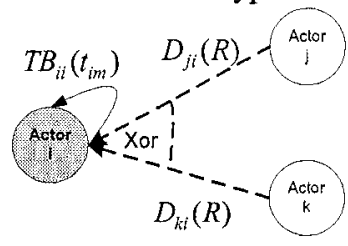

- - - "Xor" influences

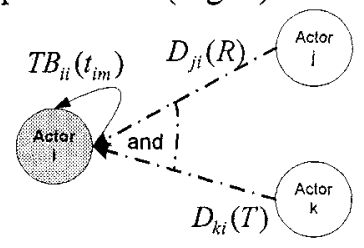

-.... . "and" influences

Figure 5 - Types of dependencies

- When the actors' influence over an actor $a_{i}$ is of the type " $\vee$ " the dependable task benefits is giving by:

Dependable Task Benefits DTB ${ }_{i j}\left(t_{i m}\right)=T B_{i j}\left(t_{i m}\right) \times \sum_{d=1}^{K} D_{d i}$

where: $\quad \mathrm{K}-$ Number of actors that influence task $t_{i m}$

- When the actors' influence over an actor $a_{i}$ is of the type " $\wedge$ " the dependable task benefits is giving by: 
Dependable Task Benefits DTB ${ }_{i j}\left(t_{i m}\right)=T B_{i j}\left(t_{i m}\right) \times \prod_{d=1}^{K} D_{d i}$

- When the actors' influence over an actor $a_{i}$ is of the type "xor" the dependable task benefits is giving by:

Dependable Task Benefits $D T B_{i j}\left(t_{i m}\right)=T B_{i j}\left(t_{i m}\right) \times \max \left\{D_{d i}\right\}$

It is also important to distinguish between influences during the execution of a task and influences during the acquisition of a business opportunity (that is acquired will imply the execution of several tasks). In this discussion we are considering the first case of influences.

If we consider that tasks performed by an actor can be divided in two groups independent and dependent - the self-benefits for $a_{i}$ can then be represented by:

Self Benefits $\left(S B_{i}\right)=\sum_{i=1}^{L} T B_{i i}\left(t_{i l}\right)+\sum_{m=1}^{M} D T B_{i i}\left(t_{i m}\right)$

where: $\quad \mathrm{L}$ - independent tasks performed by $a_{i}$ $\mathrm{M}$ - dependent tasks performed by $a_{i}$
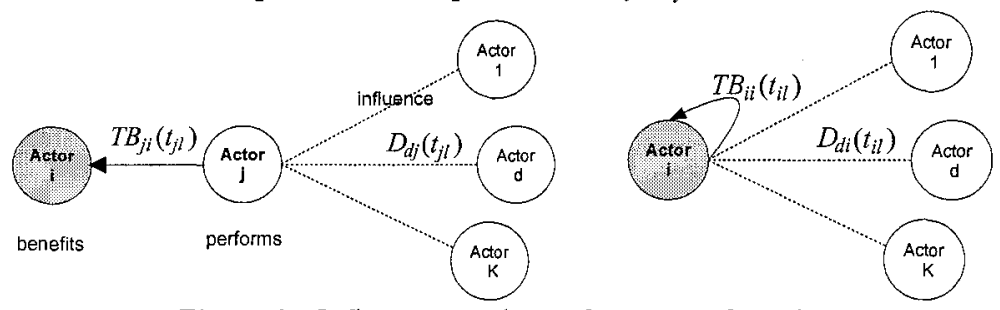

Figure 6 - Influences on the performance of a task

Similarly for received benefits:

$$
\begin{aligned}
& \text { Received Benefits }\left(R B_{i j}\right)=\sum_{l=1}^{L} T B_{j i}\left(t_{j l}\right)+\sum_{m=1}^{M} D T B_{j i}\left(t_{j m}\right) \\
& \text { where: } \quad \mathrm{L} \text { - independent tasks performed by } a_{j} \\
& \mathrm{M} \text { - dependent tasks performed by } a_{j} .
\end{aligned}
$$

\subsection{Some cooperation indicators}

In this section, some basic indicators of the cooperation process are introduced.

- Individual contribution index - normalized contribution of an actor to the collaborative network:

Individual Contribution Index $\left(I C I_{i}\right)=\frac{\text { Social Contributed Benefits }(S C B)_{i}}{\text { Total Contributed Benefits }(T C B)}$

- Apparent individual contribution index - an indicator based on the number of contribution links (i.e. the out degree of the actor in the graph representing the cooperation benefits):

Apparent contributi on index $\left(A C I_{i}\right)=\frac{N^{\circ} \text { out links leaving } a_{i}}{N-1}$

where: $\quad \mathrm{N}$ is the number of members of the collaborative network 
This index gives an apparent and simple do compute measure of the involvement of an actor as a contributor to the collaboration process. An actor with an ACI close to zero is not perceived as a good contributor to the network (although the real value of its contribution is better expressed by ICI).

- Individual external b enefits index - normalized external benefits received by an actor:

$$
\text { Individual external benefitsindex }\left(I B I_{i}\right)=\frac{\text { External Benefits }\left(E B_{i}\right)}{\text { Total Received Benefits }(T R B)}
$$

- Apparent individual benefits index - a $\mathrm{n}$ indicator based on the number of received contribution links (i.e. the in degree of the actor in the graph representing the cooperation benefits):

$$
\text { Apparent benefits index }\left(A B I_{i}\right)=\frac{N^{\circ} \text { links arriving at } a_{i}}{N-1}
$$

This index also expresses the popularity or prestige of the actor [13] in the sense that actors that are prestigious tend to receive many external benefits links.

\section{APPLICATION POTENTIAL}

The existence of a VO breeding environment (VBE) is considered by many authors as a pre-condition for the effective establishment of dynamic virtual organizations [3], [4]. A VBE represents an association or pool of organizations and their related supporting institutions that $h$ ave $b$ oth the potential and the will to c ooperate with each other through the establishment of a "base" long-term cooperation agreement. When a business o pportunity is identified b y o ne member (acting as a broker), a subset of these organizations can be selected and thus forming a VE/VO. Various VE/VOs can coexist at the same time in the context of a VBE. A breeding environment, being a long-term networked structure, presents the adequate base environment for the establishment of cooperation agreements, common infrastructures, common ontologies, and mutual trust, which are the necessary facilitating elements when building a new VE/VO. In other words, VBE represents a group of organizational entities that have developed a preparedness for cooperation, in case a specific opportunity arises. Industry clusters or industry districts are examples of such breeding environments.

In this context, the definition of a cooperation benefits model and a set of indicators can be a useful instrument to the VBE manager, to a VE/VO broker, and to a VBE member. Let's suppose a record of the past cooperation processes, represented as collaboration benefits graphs (performance catalogue), is kept at the VBE management level. Using simple calculations as illustrated in previous sections, and some simple statistics / data mining (performance and link analysis), it is possible to extract several macro and micro indicators regarding the performance of the VBE and its members as a collaborative structure. These indicators can be determined for a particular collaboration process (a particular VE/VO occurrence) or over a period of time (average values) and can be used in decision-making processes, such as planning a new VE/VO. 


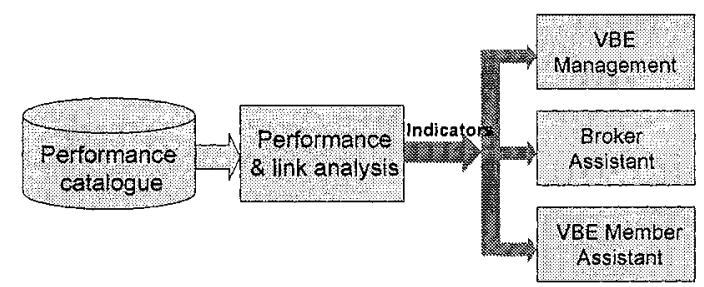

Figure 7 - Framework to support VBE to extract support indicators

For instance:

At the VBE management level:

Global indicators (e.g. cohesion level, identification of closely-related subgroups / cliques that work well together, average total benefits for all past collaborative networks /VOs, detection of "parasites"/ego-centric) or member specific indicators (e.g. average benefits generated by each member and their variance).

At the broker's level:

Indicators that may help in: partner selection for a specific VO being planned (e.g. average individual contribution index), in the analysis of the planned VO (cohesion, level of uniformity of the external benefits index, global benefits of the VO), etc. For instance, if the benefits in a particular VO are mainly self-benefits it means the level of (explicit) collaboration is low (the work could be done in isolation). For partners selection it is also important to analyze the history of dyads (an actor $a_{i}$ might be more effective when collaborating with a specific actor $a_{j}$ than with any other in the VBE). This analysis can be extended to groups larger than 2 elements (cliques).

At the member's level:

A member may ask questions such as: Shall I get involved in this consortium? Was my participation in this collaborative process beneficial to me? What is my level of "popularity" or "prestige"? What is the balance of my interactions with a specific member (dyad relationship)? Have I got reciprocity, in the past, from the potential members to be involved in the same VO?

It shall be noted that other attributes besides the benefits can be recorded associated to the benefits collaboration graph (e.g. failures, delays in delivering results). The above discussion is only an illustration of the approach being followed in a research initiative trying to contribute to the creation of a framework for VBE management. Methods developed in the Social Networks area, combined with a system to monitor and keep track of performance history, are particularly useful here. Further developments [4] and validation of the approach are nevertheless necessary.

For instance, the concepts of centrality and prestige defined in the Social Network Analysis area and typically measured with basis on the outdegrees and indegrees, respectively, need to be discussed in the VBE context. Being "central" or "prestigious" in the (limited) universe of a VBE does not necessarily mean any extra "visibility" to the outsiders (potential customers or originators of the business opportunity), but it certainly has something to do with the internal power relationships.

The assignment of values to each arc of the benefits graph might not be an easy task (when we want to record the history of performances). On the other hand, if the 
purpose is the elaboration of a simulation model to study emerging behaviors then the approach is easier to adopt as the actual values of such arcs will be parameters of the simulation process.

\section{CONCLUSIONS}

Reaching a better characterization and understanding of collaboration benefits is a key pre-condition for a wide adoption of the collaborative networks paradigm in its various manifestation forms. This understanding is also a base for the establishment of proper performance indicators to be used in decision making processes at various levels: VO breeding environment management, VO brokering, and VO breeding environment membership.

Some preliminary steps in this direction, inspired in the Social Networks analysis, were presented. Initial results illustrate the applicability of the suggested approach. Further steps are necessary towards the elaboration of the drafted analysis framework as well as its validation.

The ECOLEAD integrated project recently started in the context of the $6^{\text {th }}$ framework program of the European Commission provides the context for the continuation of this work.

\section{REFERENCES}

1. Axelroad, R. (1984). The Evolution of Cooperation, Basic Books.

2. Bar-Yam, Y. (1997). Dynamics of Complex Systems, Addison-Wesley.

3. Camarinha-Matos, L. M.; Afsarmanesh, H. (2003). Elements of a VE base infrastructure, J. Computers in Industry, Vol. 51, Issue 2, Jun 2003, pp. 139-163.

4. Camarinha-Matos, L. M.; Afsarmanesh, H. (Ed.s) (2004). Collaborative Networked Organizations - A research agenda for emerging business models, Kluwer Academic Publishers, ISBN 1-4020-7823-4.

5. Dussauge, P. and B. Garrette (1999). Cooperative Strategy - competing Successfully through Strategic Alliances, John Wiley\& Sons LDT.

6. Evans, S.; Roth, N.; Sturm, F. (2004). Performance measurement and added value of networks, in Collaborative Networked Organizations - A research agenda for emerging business models, Kluwer Academic Publishers, ISBN 1-4020-7823-4.

7. Eve, R. A., S. Horsfall, et al. (1997). Chaos, Complexity and Sociology - Myths, Models and Theories, SAGE Publications.

8. Myerson, R. B. (1997). Game Theory Analysis of Conflict, Harvard University Press.

9. Pavard, B. Complexity Paradigm as a framework for the study of Cooperative Systems http://www.irit.fr/COSI/summerschool/bpstudy.pdf - visited on (22-04-2004)

10. Penã, N. A. and J. C. F. Arroyabe (2002). Business Cooperation, Palgrave macmillan.

11. Pfeffer, J. and G. R. Salancik (1978). The External Control of Organisations: a Resource Dependence Perspective, Harper Row - New York.

12. Sterman, j. D. (2000). Business Dynamics - Systems Thinking and Modeling for Complex World, McGraw-Hill.

13. Wasserman, S. and K. Faust. (1994). Social Network Analysis - Methods and Applications. Cambridge University press.

14. Williamson, O. E. (1985). The Economic Institutions of Capitalism: Firms, Markets, Relational Contracting, New York: Free Press. 